\title{
DETERMINE DNA FRAGMENTATION IN NORMOSPERMIC AND OLIGOSPERMIC SAMPLES: A PILOT STUDY
}

\author{
Nida Zahid', Uroosa Tariq², Mohammad Tahir ${ }^{3}$, Syed Sajjad Hussain³, Rehana Rehman*2 \\ 1 Department of Surgery, Aga Khan University Karachi, Pakistan \\ 2 Department of Biological \& Biomedical Sciences, Aga Khan University, Karachi, Pakistan \\ ${ }^{3}$ Australian Concept Infertility Medical Centre, Karachi, Pakistan.
}

\begin{abstract}
Introduction: Assisted reproductive technologies (ART) plays an imperative role in infertility management. The success of ART depends on the interplay of several factors for the sustainability of sperm functions. A motile and morphologically normal sperm may have DNA fragmentation. The objective of our pilot study was to determine the status of DNA fragmentation of sperms among men presenting to an infertility Centre in Karachi, Pakistan. Assisted reproductive technologies (ART) plays an imperative role in infertility management. Methods: We conducted a pilot study at the Australian Concept Infertility Medical Centre (ACIMC), Karachi, Pakistan. We recruited 7 oligozoospermic samples and 3 normozoospermic samples according to WHO criteria (2010). The (DNA Fragmentation Index) DFI was assessed by the sperm chromatin dispersion test (SCD). The cut off for which were; < $15 \%$ fragmentation (normal), 15-30\% (moderate fragmentation) and $\geq 30 \%$ (severe DNA fragmentation). Results: DNA fragmentation was not significantly different in normozoospermic and oligospermic sample ( $p$ value $=0.3$ ). A higher proportion of oligospermic males had non-normal forms of sperms with severe DNA fragmentation i.e 5 out 7 while the normozoospermic sample had a higher proportion of normal forms of sperms with severe DNA fragmentation i.e 2 out of 3. There was moderate negative correlation between fragmented DNA \% and live count rho $=-0.642$ ( $p$ value $=0.045)$. Conclusion: We conclude that it is essential to measure the sperm DNA fragmentation when evaluating the morphologically normal cell. In future male infertility should be diagnosed based on conventional seminological parameters as well as DNA fragmentation analysis.
\end{abstract}

Keywords: DNA fragmentation, DNA Fragmentation Index, Morphology, Normozoospermic, Oligospermic, Pilot Study

\section{INTRODUCTION}

According to World Health Organization (WHO), the quality of sperm is usually defined as parameters of semen that include; count, motility, and morphology. ${ }^{1}$ These semen parameters are the predictors of reproductive competencies. Assisted reproductive technologies (ART) including in-vitro fertilization (IVF) and intracytoplasmic sperm injection (ICSI) have an imperative role in the management of infertility. The success rates of ART depends on the viability of sperms in terms of structure as well as functions., ${ }^{2,3}$

The chromosomal abnormality may account for $10-15 \%$ of severe male infertility. ${ }^{4,5}$ Genomic factors of male infertility may be accountable in the couples who fail to conceive pregnancy despite no apparent male or female infertility factors. Molecular aspects of male sperm that may contribute to infertility include; DNA damage, meiotic alterations, and aneuploidy. ${ }^{6}$ Males with genetic modifications may produce a greater proportion of sperm aneuploidies which may lead to genetic abnormality. ${ }^{4}$ Evidence from a combined data of eleven publications reported an incidence of chromosomal

Funding Information: None.

Conflict of interest: The authors declare no conflict of interest.

Submitted: 05/Oct/2018

Accepted: $26 / \mathrm{Sep} / 2020$

Study carried out at Australian Concept Infertility Medical Centre, Karachi Pakistan

Copyright Zahid et al. This is an Open Access article distributed under the terms of the Creative Commons Attribution License, which permits unrestricted use distribution, and reproduction in any medium, provided the original work is properly cited. 
abnormalities of 5.8\% among 9766 infertile males. ${ }^{7}$ Moreover, studies from India and Italy also suggest the prevalence of infertility attributed by chromosomal abnormalities of $10.2 \%$ and $13.2 \%$ respectively. ${ }^{8,9}$

ICSI circumvents the physiologic barriers at the time of penetration hence leading to fertilization. ${ }^{10} \mathrm{~A}$ single morphologically normal spermatozoon is selected in ICSI and is injected into a mature oocyte. ${ }^{11}$ The selection of sperm for ICSI is usually based on motility and morphology, with no information about the chromosomal/DNA status. ${ }^{12}$ The integrity of sperm DNA is therefore of immense importance. ${ }^{2}$ However, during ICSI there are concerns regarding the probable use of spermatozoa which have damaged DNA or chromosomal abnormalities. ${ }^{12}$ There is a positive association of teratozoospermia and varying grades of DNA damage ${ }^{13}$ although sperm morphology does not predict DNA fragmentation. ${ }^{10}$

A study suggested that infertile normozoospermic males and fertile sperm donors had lesser DNA defects as compared to men with impaired semen parameters. ${ }^{2}$ Another study suggested that normozoospermic infertile males had higher DNA damage. ${ }^{10} \mathrm{~A}$ study reported that DNA fragmentation in infertile men with severe teratozoospermia ranged from $20 \%$ to $60 \%$ and in subfertile patients with marginal sperm damage was $25 \%$, therefore a motile sperm with normal morphology may have DNA fragmentation. ${ }^{14}$ Moreover, another study suggested that when a normal spermatozoon with damaged DNA was injected in the egg cytoplasm during ICSI it resulted in poor embryo quality and pregnancy outcomes. ${ }^{15}$

Several tests are existing to evaluate sperm DNA damage that includes; "Comet, sperm chromatin dispersion (SCD or Halo), sperm chromatin structure assay (SCSA), and terminal deoxynucleotidyl transferase mediated deoxyuridine triphosphate-nick end labeling (TUNEL)". The indirect tests for measuring sperm DNA damage are SCD and SCSA while direct tests of sperm DNA breaks are Comet and TUNEL. ${ }^{16}$

Sperm DNA fragmentation and its detection in the clinical management of patients with recurrent ART failure is a subject of research. Therefore, a couple with normozoospermic sample who has undergone recurrent pregnancy loss $(\mathrm{RPL})$ may be benefitted by examination of sperm DNA fragmentation. ${ }^{16}$

Unfortunately, DNA fragmentation testing is not a routine practice in infertility clinics especially in the normozoospermic sample, causing failure of an expensive ART procedure. Therefore, it is imperative to assess DNA fragmentation in infertile males in both normozoospermic and oligospermic samples. It may help in improving ART success rates.

In the light of literature, the objective of our pilot study was to determine sperm DNA fragmentation among men presenting to an infertility Centre in Karachi, Pakistan.

We hypothesized that the DNA fragmentation will be more or less similar in the oligozoospermic and normozoospermic samples.

\section{METHODS AND MATERIALS}

This study followed recommendations of the 'Declaration of Helsinki, after approval from the Ethical Review Committee of Australian Concept Infertility Medical Centre (ACIMC). We conducted a pilot study at ACIMC Karachi, Pakistan, the rationale for conducting this pilot study was that it will permit us to do preliminary testing of our study hypothesis before conducting a large-scale study.

Fresh semen samples from the sterile recipient were obtained after taking written informed consent from males attending the clinic for infertility treatment. A total of 10 patients were recruited for this pilot study with 7 men with oligozoospermic sample (abnormal semen parameters) and 3 men with normozoospermic sample (normal semen parameters). Semen samples were classified as semen parameters according to the World Health Organization criteria. ${ }^{17}$ Abnormal semen parameters were defined as; sperm concentration less than or equal to 15 million/mL, sperm motility less than $32 \%$, and/or normal forms less than 4\%. Samples with leukocytes were excepted from the study.

\section{Semen analysis}

A semen sample was acquired by masturbation with abstinence of about 2-3 days by every participant in a sterile plastic specimen. Before the analysis, the sample was allowed to liquefy at $37^{\circ} \mathrm{C}$ for 20 minutes. Normal saline was used for sperm washing to remove the seminal plasma feathering method that was used for the washed specimen. Background staining produced clearer images of sperm in high magnification. Before staining with the Papanicolaou staining method a thin smear was formed and allowed to dry for an hour. Scoring was done on about 200 sperm cells for each specimen. Spermatozoa with a smooth oval configuration head and an acrosome that is well-defined involving about "40-70\% of the sperm head", with no neck, mid-piece, or tail defects were considered normal. While semen samples presenting less than $4 \%$ spermatozoa of normal morphology ${ }^{17}$ were considered as abnormal. The scoring of all slides was scored by one technician to prevent inter-technician inconsistency. 


\section{Sperm chromatin dispersion (SCD) test}

The sperm chromatin dispersion (SCD) test is simple, fast, and reliable for detecting sperm DNA fragmentation and does not need complex lab equipment, neither a skilled operator to infer or evaluate the results is required. It is available by the name of Halosperm. ${ }^{18}$ When sperms are positioned in agarose, denatured in acid, and then uncovered to a lysing solution, sperms with intact DNA disperse around the nucleus (generating a halo around the nucleus) while those with fragmented DNA do not disperse. Fragmented DNA sperms are prone to the introduction of single-strand DNA (ssDNA) during the acid denaturation and result in sperm with non-dispersed nuclei (very small or absent halos)..$^{18}$ The results of SCD indicates the proportion of sperms with non-dispersed nuclei.

We diluted the sperm sample in HEPES buffer medium to obtain sperm concentration that ranged between 5 and $20 \mathrm{million} / \mathrm{ml}$, transferred 50ul of sperms suspension into Eppendorf tube containing 10ul agarose gel, mixed it gently to avoid bubble formation, following placed $8 \mathrm{ul}$ of cell suspension on the center of sample well which was covered with a coverslip. We placed the slide on a cold surface and transferred it in the refrigerator at $4{ }^{\circ} \mathrm{C}$, for 5 minutes to solidify the agarose. The slide was taken out of the refrigerator and the coverslip was removed by sliding it off gently. Denaturant agent (halo sperm G2 solution 1) was applied to the well and incubated for 7 minutes. Then the reactive material was removed by tilting the slide until it completely dried up. The well was fully immersed in the Lysing solution (halo sperm G2 solution 2) and incubated for 20 minutes and was allowed to dry. The slide was then washed for 5 minutes with distilled water by using a disposable pipette. The reactive material was again removed by tilting the slide until it completely dried up. It was dehydrated by flooding with $70 \%$ ethanol for 2 minutes, drained and applied $100 \%$ ethanol for 2 minutes, drained, and allowed it to dry horizontally on filter paper. The slide was placed horizontally in an elevated position into a petri dish or a similar tray. SSA (halosperm G2 solution 3) was applied to the well and incubated for 7 minutes. Then the stain was removed by tilting until it completely dried up and the slide was placed horizontally in an elevated position. The slide was then fully immersed in SSB (halosperm G2 solution 4) and incubated for 7 minutes and the stain was again removed by tilting the slide. The excess stain was removed and was allowed to dry at room temperature. We visualized the slide under bright field microscopy and calculated the percentage of \% of non-fragmented DNA, \% of degraded DNA, and \% DNA fragmentation Index (DFI) in normozoospermic and oligospermic sample. The cut off for DFI was; < 15\% fragmentation (normal), 15-30\% (moderate fragmentation) and $\geq 30 \%$ (severe DNA fragmentation $)^{19}$

\section{Statistical Analysis}

The analysis was performed in SPSS version 22. Descriptive was performed, for quantitative variables Mean \pm S.D/Median (IQR) was reported and was assessed by independent t-test / Wilcoxon rank-sum (Mann Whitney test) respectively (as appropriate). As our sample size was small that's why the frequency in at least one of the cells was less than 5 therefore for categorical variables frequency with percentages were reported and assessed by fisher's exact test. Correlation between semen parameters was assessed by Pearson correlation $(r)$ for normally distributed data and Spearmen correlation (Rho) for non-normal data. A p-value of $<0.05$ was considered significant throughout the study.

\section{RESULTS}

Table 1, presents the semen parameters among normozoospermic males and oligozoospermic males. We enrolled 7 oligozoospermic males and 3 normozoospermic males in this pilot study. The mean age was more or less similar in both groups. The total median sperm count was significantly lower in oligospermic sample 8.5(16.5) as compared to their counterpart $41(35)$ ( $p$-value $=0.01)$. Similarly, the median live count was also significantly lower among oligospermic sample 4.5(6.5) as compared to their counterpart 24(24) ( $p$ value= 0.01). Moreover, a higher proportion of males with normozoospermic samples had normal morphology of $\geq 4$ normal forms as compared to oligospermics but the difference was not statistically significant. The mean fragmented DNA was higher among oligospermics 45.42 (10.48) as compared to their counterparts 30.0 (13.22) but the difference was not statistically significant. About $100 \%$ of oligospermic males had severe DFI of $>30 \%$ while about $66.7 \%$ of normozoospermic males had severe DNA fragmentation. However, there was an insignificant difference in DFl between the 2 groups.

There was moderate negative correlation $r=-0.687$ between age and degraded DNA\% which was statistically significant ( $p$ value $=0.031$ ). Similarly, there was a moderate negative correlation $r=-0.675$ between degraded DNA \% and NonFragmented DNA\% which was statistically significant at $p$ value $=0.03$. There was also a moderate negative correlation rho $=-0.654$ between age and DFI which was statistically significant at $p$ value $=0.04$. Moreover, there was a moderate negative correlation rho $=-0.642$ between fragmented DNA \% and live count which was statistically significant at $p$ value $=0.045$. We observed a strong positive correlation rho $=0.951$ between total count and live count which was statistically significant at $p$ value $=<0.001$. 
Table 1: Semen Parameters and DNA fragmentation in men with Oligospermic and Normozoospermic samples

\begin{tabular}{|c|c|c|c|}
\hline Semen Parameters & Oligospermic males $(n=7)$ & $\begin{array}{l}\text { Normozoospermic males } \\
\qquad(n=3)\end{array}$ & P-value \\
\hline \multicolumn{4}{|l|}{ Age (in years) } \\
\hline Mean $\pm S D$ & $34(8.16)$ & $34.33(7.23)$ & 0.95 \\
\hline \multicolumn{4}{|l|}{ Total count } \\
\hline Median (Range) & $8.5(16.5)$ & $41(35)$ & $0.01 *$ \\
\hline \multicolumn{4}{|l|}{ Live Count } \\
\hline Median (Range) & $4.50(6.5)$ & $24.00(24)$ & $0.01 *$ \\
\hline \multicolumn{4}{|l|}{ Normal Morphology } \\
\hline$<4 \%$ & $5.00(71.4)$ & $1.0(33.3)$ & 0.50 \\
\hline$\geq 4 \%$ & $2.00(28.6)$ & $2.00(66.7)$ & \\
\hline Mean \pm SD & $2.43(1.90)$ & $3.66(7.57)$ & 0.315 \\
\hline \multicolumn{4}{|l|}{ Non Fragmented DNA (\%NFD) } \\
\hline Mean $\pm S D$ & $43.28(10.43)$ & $55.33(29.83)$ & 0.56 \\
\hline \multicolumn{4}{|l|}{ Fragmented DNA (\%FD) } \\
\hline Mean $\pm S D$ & $45.42(10.48)$ & $30.0(13.22)$ & 0.95 \\
\hline \multicolumn{4}{|l|}{ Mean \pm SD } \\
\hline \multicolumn{4}{|l|}{ DFI(DNAFragmentation Index) } \\
\hline$<15 \%$ (Normal) & $0.00(0)$ & $0.00(0)$ & 0.3 \\
\hline 15-30\%(Mild Fragmentation) & $0.00(0)$ & $1.00(33.3)$ & \\
\hline >30\%(Severe Fragmentation) & $7.00(100)$ & $2.00(66.7)$ & \\
\hline Median(Range) & $60.00(30)$ & $30.00(54)$ & 0.424 \\
\hline
\end{tabular}

*P-value significant at $<0.05$ by Wilcoxon rank-sum test

Oligopermic males had non-normal forms of sperms with severe DNA fragmentation i.e 5 out 7 while the normozoospermic sample had a higher proportion of normal forms of sperms with severe DNA fragmentation i.e 2 out of 3.

\section{DISCUSSION}

Our study results indicate that the total median sperm count, live sperm count, and normal morphology of sperms were higher in normozoospermic samples as compared to oligospermic samples. A moderate negative correlation between fragmented DNA \% and live count indicating that higher the live count is lower will be the DNA fragmentation. A study also reported that sperm viability is significantly related to DNA fragmentation rates. ${ }^{20}$ In our study sample though the normozoospermic samples had a better live count and normal morphology as compared to oligospermic samples yet the DNA fragmentation was still equally higher in the normal forms of the normozoospermic sample as was in the non-normal form of the oligospermic sample. The DFI of $>30 \%$ (severe DNA fragmentation) was more or less similar in both the groups. This indicates that a normozoospermic sample can have high DNA fragmentation and may result in ART failure.

Literature suggests that DNA damage hampers the normal conception and led to recurrent ICSI failures..$^{10}$ Another study also suggested that DNA fragmentation ranged from $20 \%$ to $60 \%$ among infertile men with severe Teratozoospermia. DNA fragmentation can thus be present in a motile and morphologically normal sperm. ${ }^{14}$ Hence, a higher number of patients with unexplained (normozoospermic) infertility may exhibit remarkably high degrees of fragmented sperm DNA. ${ }^{21}$ Therefore, even normozoospermic couples might get help from this test as far as ICSI results are concerned. ${ }^{16} \mathrm{~A}$ 
study indicated that even the normal spermatozoa which had damaged DNA resulted in poor embryo quality and negative pregnancy outcomes after ICSI. ${ }^{15}$ Therefore, DFI may enhance the impact of a semen analysis to predict the chances of normal conception after ICSI. ${ }^{22}$

Disturbance in glucose homeostasis causes long-term injuries to male reproductive organs with dysfunctions in sperm motility, sperm DNA integrity, and fertilization ability capability. This can be explained based on disturbances in epigenetic regulation responsible for chromatin alterations. ${ }^{23}$ The DFI can thus be used for the identification of DNA damage in infertile male subjects with Diabetes Mellitus or impaired glucose tolerance. Our study results also indicate a moderate negative correlation between age and degraded DNA\% and DFI \%, which shows that with increasing age the degradation of DNA decreases. Although the literature shows a positive correlation between age and degraded DNA $\%,{ }^{24}$ we assume that inconsistency of our study results with literature may be due to our small sample size.

There are were several limitations to our study; 1 . The sample size was small; therefore, the results cannot be generalizable. However, DNA fragmentation testing is an expensive procedure therefore before a large-scale study we wanted to assess it in a small-scale study 2. Unfortunately, occupational factors and other important risk factors such as the use of addictives, etc. could not be collected. However, in a larger-scale study, we will obtain all the required information so that we can assess the impact of other risk factors from the environment and lifestyle on DNA fragmentation. Modifiable risk factors on sperm parameters were identified in our population ${ }^{25}$ but their effect was not observed on DNA fragmentation.

There were several strengths of our study; 1. A robust method of 'DNA fragmentation' testing by sperm chromatin dispersion (SCD) test was used. 2. The assessment of normozoospermic and oligospermic samples was assessed by trained embryologist following the criteria of $\mathrm{WHO}^{17} 3$. This preliminary study will enable us and other scientists to conduct large scale studies for testing DNA fragmentation which is an expensive procedure. In addition to semen parameters, DNA fragmentation analysis will help in the prediction of the success of ART.

\section{CONCLUSION AND RECOMMENDATIONS}

We conclude that the evaluation of sperm DNA fragmentation is important when assessing the morphologically normal cell population. DFI plays an important predictor for the chance of natural conception. DFI increases the impact of semen analysis in the management of infertile couples. In the future, we recommend that male infertility diagnosis should depend on routine semen analysis as well as DNA fragmentation in normozoospermic and oligospermic samples especially before going for ART. However, we recommend that large-scale studies should be conducted to homogenize the factors for the management of specific features of male infertility

\section{ACKNOWLEDGMENTS}

We are thankful to the Australian Concept Infertility Medical Centre and Department of Biological \& Biomedical Sciences for their collaborative support.

\section{REFERENCES}

1. Rehman R, Zafar A, Fatima SS, Mohib A, Sheikh A. Altered sperm parameters and subclinical hypothyroidism: a cross sectional study in Karachi, Pakistan. Int J Clin Pract. 2020;74(9):e13555. http://dx.doi.org/10.1111/ijcp.13555. PMid:32453880.

2. Varghese A, Bragais F, Mukhopadhyay D, Kundu S, Pal M, Bhattacharyya AK, et al. Human sperm DNA integrity in normal and abnormal semen samples and its correlation with sperm characteristics. Andrologia. 2009;41(4):207-15. http://dx.doi. org/10.1111/j.1439-0272.2009.00917.x. PMid:19601931.

3. Nayan M, Punjani N, Grober E, Lo K, Jarvi K. The use of assisted reproductive technology before male factor infertility evaluation. Transl Androl Urol. 2018;7(4):678-85. http://dx.doi.org/10.21037/tau.2018.06.08. PMid:30211059.

4. Ferlin A, Arredi B, Foresta C. Genetic causes of male infertility. Reprod Toxicol. 2006;22(2):133-41. http://dx.doi.org/10.1016/j. reprotox.2006.04.016. PMid:16806807.

5. Harton GL, Tempest HG. Chromosomal disorders and male infertility. Asian J Androl. 2012;14(1):32-9. http://dx.doi.org/10.1038/ aja.2011.66. PMid:22120929.

6. Sakkas D, Alvarez JG. Sperm DNA fragmentation: mechanisms of origin, impact on reproductive outcome, and analysis. Fertil Steril. 2010;93(4):1027-36. http://dx.doi.org/10.1016/j.fertnstert.2009.10.046. PMid:20080235.

7. Dohle GR, Colpi GM, Hargreave TB, Papp GK, Jungwirth A, Weidner W. EAU guidelines on male infertility. Eur Urol. 2005;48(5):70311. http://dx.doi.org/10.1016/j.eururo.2005.06.002. PMid:16005562.

8. Poongothai J, Gopenath TS, Manonayaki S. Genetics of human male infertility. Singapore Med J. 2009;50(4):336-47. PMid:19421675. 
9. Gianaroli L, Magli MC, Cavallini G, Crippa A, Nadalini M, Bernardini L, et al. Frequency of aneuploidy in sperm from patients with extremely severe male factor infertility. Hum Reprod. 2005;20(8):2140-52. http://dx.doi.org/10.1093/humrep/dei033. PMid:15845594.

10. Avendaño C, Oehninger S. DNA fragmentation in morphologically normal spermatozoa: how much should we be concerned in the ICSI era? J Androl. 2011;32(4):356-63. http://dx.doi.org/10.2164/jandrol.110.012005. PMid:21088229.

11. Palermo G, Joris H, Devroey $P$, Van Steirteghem AC. Pregnancies after intracytoplasmic injection of single spermatozoon into an oocyte. Lancet. 1992;340(8810):17-8. http://dx.doi.org/10.1016/0140-6736(92)92425-F. PMid:1351601.

12. Aitken RJ, De luliis GN. Origins and consequences of DNA damage in male germ cells. Reprod Biomed Online. 2007;14(6):727-33. http://dx.doi.org/10.1016/S1472-6483(10)60676-1. PMid:17579989.

13. Tang S, Gao H, Zhao Y, Ma S. Aneuploidy and DNA fragmentation in morphologically abnormal sperm. Int J Androl. 2010;33(1):e16379. http://dx.doi.org/10.1111/j.1365-2605.2009.00982.x. PMid:19732195.

14. Avendaño C, Franchi A, Taylor S, Morshedi M, Bocca S, Oehninger S. Fragmentation of DNA in morphologically normal human spermatozoa. Fertil Steril. 2009;91(4):1077-84. http://dx.doi.org/10.1016/j.fertnstert.2008.01.015. PMid:18440529.

15. Avendaño C, Franchi A, Duran H, Oehninger S. DNA fragmentation of normal spermatozoa negatively impacts embryo quality and intracytoplasmic sperm injection outcome. Fertil Steril. 2010;94(2):549-57. http://dx.doi.org/10.1016/j.fertnstert.2009.02.050. PMid:19339003.

16. Bach PV, Schlegel PN. Sperm DNA damage and its role in IVF and ICSI. Basic Clin Androl. 2016;26(1):15. http://dx.doi.org/10.1186/ s12610-016-0043-6. PMid:27980786.

17. Cooper TG, Noonan E, Von Eckardstein S, Auger J, Baker HW, Behre HM, et al. World Health Organization reference values for human semen characteristics. Hum Reprod Update. 2010;16(3):231-45. http://dx.doi.org/10.1093/humupd/dmp048. PMid:19934213.

18. Fernández JL, Johnston S, Gosálvez J. Sperm Chromatin Dispersion (SCD) Assay. A Clinician's Guide to Sperm DNA and Chromatin Damage. Springer, 2018, pp.137-152. . http://dx.doi.org/10.1007/978-3-319-71815-6_8.

19. Chohan KR, Griffin JT, Lafromboise M, De Jonge CJ, Carrell DT. Comparison of chromatin assays for DNA fragmentation evaluation in human sperm. J Androl. 2006;27(1):53-9. http://dx.doi.org/10.2164/jandrol.05068. PMid:16400078.

20. Samplaski MK, Dimitromanolakis A, Lo KC, Grober ED, Mullen B, Garbens A, et al. The relationship between sperm viability and DNA fragmentation rates. Reprod Biol Endocrinol. 2015;13(1):42. http://dx.doi.org/10.1186/s12958-015-0035-y. PMid:25971317.

21. Oleszczuk K, Augustinsson L, Bayat N, Giwercman A, Bungum M. Prevalence of high DNA fragmentation index in male partners of unexplained infertile couples. Andrology. 2013;1(3):357-60. http://dx.doi.org/10.1111/j.2047-2927.2012.00041.x. PMid:23596042.

22. Giwercman A, Lindstedt L, Larsson M, Bungum M, Spano M, Levine RJ, et al. Sperm chromatin structure assay as an independent predictor of fertility in vivo: a case-control study. Int J Androl. 2010;33(1):e221-7. http://dx.doi.org/10.1111/j.1365-2605.2009.00995.x. PMid:19840147.

23. Ding G-L, Liu Y, Liu M-E, Pan JX, Guo MX, Sheng JZ, et al. The effects of diabetes on male fertility and epigenetic regulation during spermatogenesis. Asian J Androl. 2015;17(6):948-53. http://dx.doi.org/10.4103/1008-682X.150844. PMid:25814158.

24. Komiya A, Kato T, Kawauchi Y, Watanabe A, Fuse H. Clinical factors associated with sperm DNA fragmentation in male patients with infertility. ScientificWorldJournal. 2014;2014:868303. http://dx.doi.org/10.1155/2014/868303. PMid:25165747.

25. Zahid N, Saleem S, Azam I, Moatter T. Association of obesity with Infertility among Pakistani men: a case control study. Open J Epidemiol. 2015;5(3):204-15. http://dx.doi.org/10.4236/ojepi.2015.53025.

\author{
*Corresponding Author \\ Dr. Rehana Rehman \\ Biological and Biomedical Sciences, Faculty of Health Sciences, Medical College \\ The Aga Khan University, Stadium Road, P.O. Box 3500 \\ Karachi-74800, Pakistan. \\ Telephone: 92-21-34864564 \\ Email: rehana.rehman@aku.edu
}

\title{
Author information
}

Nida Zahid: MBBS, M.Sc in Epidemiology \& Biostatistics; Uroosa Tariq: M.Phil in Biochemstry; Mohammad Tahir: Masters in Biotechnology; Syed Sajjad Hussain: MBBS; Rehana Rehman: MBBS, M.Phil, PhD in Physiology.

\section{Author contributions}

Nida Zahid conceived the idea; Uroosa Tariq, Mohammad Tahir and Dr. Naseer Ahmad collected the samples and performed the experiment. Rehana Rehman supervised the project. All authors took part in writing of manuscripts. 